\title{
Genetic Vaccination as a Flexible Tool to Overcome the Immunological Complexity of Invasive Fungal Infections
}

\author{
Laura Luberto ${ }^{1 *}$, Bruna Neroni ${ }^{2}$, Orietta Gandini ${ }^{3}$, Ersilia Vita Fiscarelli ${ }^{2}$, \\ Giovanni Salvatori', Giuseppe Roscilli ${ }^{1}$ and Emanuele Marra ${ }^{1 *}$ \\ ${ }^{1}$ Takis s.r.l., Rome, Italy, ${ }^{2}$ Cystic Fibrosis Diagnostic Section, U.O. Microbiology and Immunology Diagnostic, Department \\ of Immunology and Laboratory Medicine, Children's Hospital Bambino Gesù Organization IRCCS, Rome, Italy, ${ }^{3}$ Department \\ of Molecular Medicine, Sapienza University of Rome, Rome, Italy
}

OPEN ACCESS

Edited by:

Malcolm Scott Duthie,

HDT Biotech Corporation,

United States

Reviewed by:

Charalampos Dokos,

Aristotle University of Thessaloniki,

Greece

Joshua J. Obar,

Dartmouth College, United States

*Correspondence:

Laura Luberto luberto@takisbiotech.it

Emanuele Marra

marra@takisbiotech.it

Specialty section:

This article was submitted to Microbial Immunology,

a section of the journal

Frontiers in Microbiology

Received: 05 October 2021 Accepted: 25 November 2021 Published: 15 December 2021

Citation:

Luberto L, Neroni B, Gandini O, Fiscarelli EV, Salvatori G, Roscilli $G$ and Marra E (2021) Genetic

Vaccination as a Flexible Tool

to Overcome the Immunological

Complexity of Invasive Fungal

Infections.

Front. Microbiol. 12:789774. doi: 10.3389/fmicb.2021.789774
The COVID-19 pandemic has highlighted genetic vaccination as a powerful and costeffective tool to counteract infectious diseases. Invasive fungal infections (IFI) remain a major challenge among immune compromised patients, particularly those undergoing allogeneic hematopoietic bone marrow transplantation (HSCT) or solid organ transplant (SOT) both presenting high morbidity and mortality rates. Candidiasis and Aspergillosis are the major fungal infections among these patients and the failure of current antifungal therapies call for new therapeutic aids. Vaccination represents a valid alternative, and proof of concept of the efficacy of this approach has been provided at clinical level. This review will analyze current understanding of antifungal immunology, with a particular focus on genetic vaccination as a suitable strategy to counteract these diseases.

Keywords: genetic vaccination, invasive fungal infections, aspergillosis, vaccine, immunotherapy, anti-fungal, SOT, HSCT

\section{INTRODUCTION}

Nearly a billion people are estimated to have skin, nail, and hair fungal infections and more than 150 million people have serious fungal diseases, which have a major impact on their lives or are fatal. Aspergillus and Candida remain the main fungal pathogens responsible for a high number of cases of serious fungal disease (Schmiedel and Zimmerli, 2016). Mortality for these types of infection range between 25 and 90\%, depending on the severity of the underlying clinical conditions (Lass-Flörl, 2009). The major target of invasive aspergillosis and candidemia are patients who experience hematopoietic bone marrow transplantation (HSCT) and Solid organ transplant (SOT). Chronic pulmonary aspergillosis is globally estimated in 3,000,000 cases, $\sim 700,000$ cases of invasive candidiasis, and $\sim 250,000$ cases of invasive aspergillosis occur annually (Bongomin et al., 2017). The overall incidence of IFIs in hematopoietic stem cell transplant (HSCT) patients was 3.4\%. Invasive aspergillosis (IA) is the most common IFI encountered in the HSCT population: Aspergillus accounted for $43 \%$ of infections and Candida accounted for $28 \%$. The remaining $29 \%$ is associated to other fungal infections (Kontoyiannis et al., 2010). In allogeneic HSCT recipients, there are three periods of risk for IA: (1) neutropenia after the conditioning regimen; (2) exogenous 
immunosuppression for prevention or treatment of acute Graft Versus Host Disease (GVHD); and (3) exogenous immunosuppression for treatment of chronic GVHD (after day 100 following transplant) (Person et al., 2010). Among solid organ transplant (SOT) recipients, more than $50 \%$ of all fungal infections were due to Candida, except for lung transplant recipients, where Aspergillus was the most common fungal pathogen, and which were responsible for $70 \%$ of IFIs (Marr et al., 2002). Unquestionably in SOT patients, rejection and exogenous immunosuppressive agents, particularly high-dose steroids and antilymphocyte treatments, lead to an increased risk of the onset of IFIs in this population (Gavaldà et al., 2014). Despite current antifungal therapies there is still a considerable proportion of cases of fungal infections that remain without a cure. Antifungal resistance represents a major clinical challenge for treating invasive fungal infections (IFI) that could be as high as 20 (Wiederhold, 2017). Current antifungal drugs may be limited by drug-drug interactions and serious adverse effects/toxicities in severely ill patients and prevent their prolonged use or dosage increase (Robbins et al., 2016; Tverdek et al., 2016). Thus, enlarging the arsenal of systemically available antifungals and developing alternative strategies to pharmacological intervention becomes increasingly necessary. Immunotherapies represent a valid alternative or a synergic support to current antifungal (Robbins et al., 2016; Tverdek et al., 2016) therapies and include a wide range of approaches (Sam et al., 2018; Table 1). Despite preclinical evidence of the efficacy of vaccination in both bone marrow transplanted and corticosteroid immunosuppressed mice (Ito and Lyons, 2002; Bozza et al., 2009), the main issue to be solved is whether vaccination could be an effective strategy to prevent and cure fungal infection also in patients whose immune system is severely impaired/compromised (Scriven et al., 2017).

\section{VACCINATION AGAINST FUNGAL INFECTION}

Our understanding of fungal immunity have increased the prospect of developing vaccines against fungi that are effective, safe, and able to elicit lasting immunity even in immune deficient individuals (Espinosa and Rivera, 2016; Nami et al., 2019). Genetic immunization has been shown to induce humoral as well as cellular immune responses with high efficacy (Bolhassani and Yazdi, 2009) and has the potential to guide the host immune response by co-expressing immunomodulatory and costimulatory molecules (Kutzler and Weiner, 2008). Genetic vaccines have been widely used against numerous pathogens, and current experience with COVID-19 has raised new hopes about the effective use of this strategy in other infectious diseases (Abu Abed, 2021). Genetic vaccination offers the opportunity to easily screen for a wide number of microbial antigens, thus enhancing the chances of success. Considering the complexity of the host immune response to the fungus, particularly in immunocompromised patients, a highly flexible vaccination strategy is extremely desirable. The sequencing of fungal genomes has identified key functional factors essential to fungal survival and virulence in the human host (Iyalla, 2017; Priest et al., 2020) and has helped to understand how the fungus evades the immune system or establishes infection (Hogan et al., 1996). This analysis would be of help in at least four different ways. First, an ideal target would protect against infection from multiple species of fungi by containing conserved epitopes that elicit both $\mathrm{T}$ and $\mathrm{B}$ cell responses. Second, sequence comparison of genes from different fungi may help to identify clusterrelated genes with the potential of becoming the targets of pan fungal vaccines with a broad spectrum of activity. Studies on preclinical models of pan vaccination have demonstrated a protective cross reactive immune response against different fungi (Hamad, 2012; Champer et al., 2016). Third, sequence analysis would help to identify the best immunogenic proteins, preferably those secreted or expressed on the cell wall (Musso et al., 1998). Fourth, given the possible homologies between fungal and human proteins, the fungal target sequence selected must be markedly dissimilar to any human one (Edwards, 2012). A proof of concept that vaccination is an effective strategy to counteract fungal diseases is provided by studies in several models of invasive fungal infection. Vaccination with recombinant Aspergillus fumigatus Asp f3 (Pmp20) protected mice from aspergillosis following neutropenia or corticosteroid induced immunosuppression (Bozza et al., 2002; Ito et al., 2006, 2009; Diaz-Arevalo et al., 2011, 2012). Vaccine formulations with Crf1 Gel1, and Pep2 (Bozza et al., 2009; Stuehler et al., 2011) provided protection against aspergillosis in comparable experiments. Protection from candidemia has been conferred by immunization with recombinant Mdh1, Sap2, and Als3 (Vilanova et al., 2004; Spellberg et al., 2008; Shibasaki et al., 2014) with the last two investigated in clinical trials (Schmidt et al., 2012; Cassone, 2013). However, the use of recombinant fungal proteins for vaccination has some important limitations which in part explain why no anti-fungal vaccine has been approved to date by a regulatory agency. Processes to produce a recombinant protein could be cumbersome, requiring costly resources and lengthy production times. In this context genetic vaccination could represent a valid strategy for antifungal vaccination.

\section{Genetic Vaccination-General Features}

Cross talk between innate and adaptive immunity arms of the immune system is essential for the resolution of fungal infection. Interruption of this connection by iatrogenic drugs or depletion of key immunity cells due to ablative chemotherapies imbalances the host immune response and predisposes to fungal infection. In IFI, Th1-biased based immune responses correlate with protective immunity and resistance, whereas type 2 helper $\mathrm{T}$ (Th2)-based responses generally lead to an exacerbation of the disease. Th1 cell activation is instrumental to clearing infection by improving the effector function of innate immune cells through the release of pro-inflammatory cytokines (Pathakumari et al., 2020). Any vaccination strategy must be able to redirect this imbalance toward an effective immune response against the fungus. Genetic vaccines have become an attractive approach for generating antigen-specific immune responses (Bolhassani and Yazdi, 2009; Flingai et al., 2013). A protein expressed by a genetic vaccine displays its native conformation with the relevant post-translational modifications, which are required to elicit both 
TABLE 1 | Summary of the attempted immunotherapies to date.

Immunotherapeutic approaches in fungal diseases

Strategy

Recombinant cytokines and immune activating compounds

Colony-stimulating factors (G-CSF, GM-CSF)

IFN $\gamma$

$\mathrm{TNF}-\alpha$

$\mathrm{IL}-12$

IL-15

Thymosin- $\alpha-1$ (T $\alpha 1)$

\section{Cell therapy}

Neutrophil enrichment by Granulocyte

Transfusion (GTX)

Dendritic cell (DC) immune therapy

NK cell therapy

Adoptive T cell transfer

Chimeric antigen receptor (CAR) T cell therapy

Antibody therapy

Anti-beta-glucan monoclonal antibodies

Anticryptococcal monoclonal antibody

Checkpoint inhibitors

Vaccination strategies

Live attenuated virus

Formalin killed Coccidioides immitis spherules

Heat killed Saccaromyces cerevisiae (KHS)

Attenuated strain of Coccidiodes posadasii

Deletion of Blastomyces adhesion-1 (Bad-1)

gene

Attenuated strain of Criptococcus neoformans

(H99g)

Live attenuated strain of Tricoptyton

verrucosum

\section{Conjugates}

B-glucan polysaccharide from brown algae with inactivated diphtheria toxin (CRM)

B-1,2 mannotrios with fructose biphosphate aldolase (Fba)

Capsular polysaccharide antigen of

Cryptococcus neoformans (GXM) with tetanus

toxoid

\section{Recombinant/subunit}

NDV-3 Agglutinin-like sequences (Als3-p) for

Candida spp.

Secreted aspartyl proteinase-2 (Sap-2) for

Candida spp.

\section{Candida, Cryptococcus}

Aspergillus, Candida

Aspergillus

Candida albicans, Cryptococcus neoformans,

Aspergillus fumigatus

Candida albicans, Aspergillus

fumigatus, Fusarium spp., and

Scedosporium spp.

Candida albicans

Aspergillus fumigatus

Aspergillus fumigatus, Candida albicans

Aspergillus

Aspergillus

Candida albicans

Cryptococcus neoformans

Aspergillus

Coccidioides immitis

Coccidioides posadasii,

Candida albicans, Aspergillus

fumigatus

Coccidioides posadasii

Blastomyces dermatitidis

Cryptococcus neoformans

Trichophyton verrucosum

Candida albicans, Aspergillus fumigatus

Candida albicans

Cryptococcus neoformans

Candida albicans

Candida spp.
Experimental study level

Preclinical and clinical

Clinical

Preclinical and clinical

Preclinical

In vitro

Preclinical

Clinical

In vitro and preclinical

In vitro and clinical

Clinical

Preclinical

In vitro and preclinical

Preclinical and clinical

In vitro and preclinical

Preclinical and clinical

Preclinical

Preclinical

Preclinical

Preclinical

Preclinical

Preclinical

Preclinical

Preclinical

Clinical

Preclinical and clinical

\section{References}

Safdar et al., 2013; Mezidi et al., 2014; Wan et al., 2015

Nagai et al., 1995; Sainz et al., 2007; Buddingh et al., 2015

Romani et al., 1997; Mehrad et al., 1999

Decken et al., 1998

Musso et al., 1998; Winn et al., 2003

di Francesco et al., 1994

Seidel et al., 2008

Banchereau and Steinman, 1998;

Ramirez-Ortiz et al., 2011

Voigt et al., 2014; Stuehler et al., 2015

Perruccio et al., 2005; Bacher et al., 2015

Kumaresan et al., 2014

Torosantucci et al., 2009

Larsen et al., 2005; Rachini et al., 2007

Stephen-Victor et al., 2017

Ardiani et al., 2010

Capilla et al., 2009; Ardiani et al., 2010; Liu et al., 2011

Xue et al., 2009

Brandhorst et al., 1999; Wüthrich et al., 2000

Cox and Magee, 1998; Wozniak et al., 2011

Gudding and Naess, 1986

Torosantucci et al., 2005

Xin et al., 2012

Devi, 1996

Phan et al., 2007

De Bernardis et al., 2012; Santos and Levitz, 2014 
humoral and cell mediated neutralizing immune responses to conformational epitopes (Bolhassani and Yazdi, 2009). Genetic vaccines can be easily prepared on a large scale with high purity and stability in relation to proteins and other biological polymers. In addition this strategy allows artificial immunogens and coexpression of immunomodulatory proteins to be engineered (Sharma and Khuller, 2001). Among these: targeting antigens for rapid intracellular degradation, directing antigens to APCs by fusion to ligands for APC receptors, co-translating antigens with chemokines and cytokines or with co-stimulatory molecules and coadministration with $\mathrm{CpG}$ oligonucleotides (Sharma and Khuller, 2001). The plasticity of genetic vaccination could be of importance in those contexts where immunosuppressive therapies alter the normal homeostasis of the innate and adaptive immune system. This type of approach has been evaluated in other fungal infections such as Paracoccidiodomycosis, Coccidiomycosis, and Pneumocystosis (Ivey et al., 2003; Zheng et al., 2005; de Amorim et al., 2013).

\section{Genetic Vaccination on Fungal Infection Paracoccidioidomycosis}

Paracoccidioidomycosis (PCM) is an important endemic mycosis in Latin America with significant morbidity and mortality (Marques et al., 2006; de Almeida et al., 2018). There are two recognized Paracoccidioides species, P. brasiliensis and P. lutzii. Approximately $1,853(\sim 51.2 \%)$ of 3,583 confirmed deaths in Brazil due to systemic mycoses from 1996 to 2006 were caused by PCM. Antifungal treatment is required for patients with PCM. The initial treatment lasts from 2 to 6 months and sulfa derivatives, amphotericin $\mathrm{B}$, azoles and terbinafine are used in clinical practice; however, despite prolonged therapy, relapses are still a problem. An effective Th1-biased cellular immune response is essential to control the disease, which can be induced by exogenous antigens or modulated by prophylactic or therapeutic vaccines (Taborda et al., 2015). An initial vaccine consisting of 15 amino acid peptides, named P10 peptide, derived from the immunodominant antigen gp43 of Paracoccidioides brasiliensis was evaluated in a mouse model of intratracheal infection. This peptide was shown to elicit a protective Th-1 response and, when used in combination with the standard chemotherapy regimens for experimental PCM, improved treatment efficacy (Taborda et al., 1998; Marques et al., 2006; Silva et al., 2008). Successively, a plasmid DNA containing the minigene encoding the P10 peptide, which includes the T-cell epitope of gp43, was evaluated in the same model of infection. Animals immunized with the plasmid pcDNA3-P10 showed a significant reduction in the pulmonary fungal burden when compared to non-immunized and only plasmid vector immunized mice after intratracheal infection. This vaccine increased the percentage of $\mathrm{CD}^{+}$and CD44hi memory $\mathrm{T}$ cells and Foxp $3^{+}$Treg cells in the spleens and lungs of immunized mice, reinforcing the concept that the presence of $\mathrm{T}$ regulatory cells upon secondary antigen exposure may prevent immunopathology in the context of vaccination and favor long-term memory. Furthermore, the pattern of cytokines released by the splenocytes from mice immunized with pcDNA3P10 is consistent with a Th1-biased T-cell immune response (de Amorim et al., 2013), which is predictive of a positive clinical response as discussed above.

\section{Coccidioidomycosis}

Coccidioides immitis and C. posadasii are two highly pathogenic dimorphic fungal species that cause coccidioidomycosis (also known as Valley Fever). They are endemic in the arid region from west Texas to southern and central California in the United States and up to 50\% of long-term residents get infected. Pulmonary symptoms are the most common, but it is estimated that only $30-50 \%$ of infections are symptomatic. Fewer than $5 \%$ of immunocompetent patients develop disseminate disease. Coccidioides immitis or Coccidioides pusadassi are prime candidates for vaccine development (Yoon and Clemons, 2013). Primary infection, acquired via inhalation of the arthroconidia, is manifested by a benign or asymptomatic infection; however, others can go on to develop acute or chronic disease involving the lungs and/or extrapulmonary organs (Galgiani et al., 2005; McCotter et al., 2019). The acquired immunity that develops after active infection testifies to the feasibility of a vaccine for this disease (Cox and Magee, 1998). In 1995, Barry et al. (1995) published a technique, termed "expression library immunization” (ELI) for identifying protective genes. Immunizing with sequentially divided protective fractions of a genomic library has the potential to screen every gene in the pathogen's genome and to offer the advantage of presenting the host with multiple genes, thereby simulating the effects of a live organism. Using ELI, investigators have identified protective genes in in a number of infection diseases (Barry et al., 2004). Following this type of approach, Ivey et al. (2003) identified a Coccidioides gene named ELIAg1 that has protective capacity in BALB/c mice against intraperitoneal challenge with 2,500 arthroconidia of this fungus. The gene was isolated from an original pool of $800-1,000$ genes by successive fractionation of a cDNA library prepared from parasitic spherule-phase cells. The ELI has proven to be a useful strategy for identifying protective gene pools and offers the decided advantage of not requiring a priori knowledge of whether protection is mediated by cell-mediated or humoral immunity.

Direct comparison of vaccine efficacy against Coccidioidomycosis between recombinant antigen 2 (Ag2), a Coccidioides immitis isolated glycoprotein, and the same antigen cDNA expressed in a plasmid vector was performed by Jiang et al. (1999a). Genetic immunization with the plasmid vector encoding Ag2 enhanced survival of BALB/c mice challenge with C. immitis arthroconidia while it did not occurred in mice immunized with the recombinant antigen. This genetic vaccine co-expressing IL12 and Ag2 enhanced protective immunity against Coccidioides immitis through the induction of Th1-associated immune responses (Jiang et al., 1999b).

\section{Pneumocystosis}

$P$. jirovecii is the etiological agent of Pneumocystis pneumonia (PCP), causing an asymptomatic or mild infection in the normal host but fulminate pneumonia in the immunocompromised host. It accounts for an estimated 10,000 hospitalizations in the 
United States and > 400,000 cases worldwide each year. Even with treatment, mortality rates approach $10-20 \%$. An overview of the immune response to Pneumocystis and current progress on novel vaccines and therapies is discussed in Gingerich et al. (2021). Despite current strategies to treat HIV infection and its complications, Pneumocystis (PC) pneumonia remains a common clinical problem (Morris et al., 2004) thus there is a need to develop $\mathrm{CD}^{+}{ }^{+} \mathrm{T}$ cell-independent therapeutic strategies to prevent this infection. It has been demonstrated that overexpression of IFN- $\gamma$ can result in eradication of PC in the absence of CD4 ${ }^{+} \mathrm{T}$ cell help (Kolls et al., 1999), in part through augmenting IFN-g-secreting type I (Tc1) $\mathrm{CD}^{+} \mathrm{T}$ cell response (McAllister et al., 2004). Another molecule expressed on activated $\mathrm{CD} 4{ }^{+} \mathrm{T}$ cells that is critically important for co-stimulation and $\mathrm{CD}^{+}{ }^{+} \mathrm{T}$ cell help is CD40L, that activates DCs to influence $\mathrm{CD}^{+}$cytotoxic T cell (Banchereau and Steinman, 1998; Grewal and Flavell, 1998) and B cell (Clark and Ledbetter, 1994) immune responses. It has been demonstrated that CD40L gene modified DCs pulsed with Pseudomonas aeruginosa (PA) could stimulate naive $\mathrm{B}$ cells to produce anti-PA antibodies and confer protection against PA challenge. Furthermore, CD40L-modified DCs pulsed with $\mathrm{PC}$ resulted in a protective antibody response in $\mathrm{CD} 4$ depleted mice and protected them against a PC challenge (Keely et al., 2003), thus indicating that immunotherapeutic approaches may represent a valid alternative to counteract PC infection. Zheng et al. (2005) identified on the surface of PC a protein named Kexin and have used it to validate DNA vaccination in CD4-depleted mice. Immunization with plasmid expressing Kexin under CMV promoter resulted in significant anti-PC IgG1 and IgG2a titers in CD4-competent mice, whereas titers were significantly lower in CD4-depleted mice. In comparison, CD4-depleted mice immunized with a plasmid expressing both Kexin and CD40L demonstrated significantly higher titers of anti-PC IgG1 compared with CD4-depleted mice immunized with the plasmid expressing only Kexin. Mice immunized with a plasmid expressing only CD40L or an empty vector alone, demonstrated no detectable anti-PC titer. DNA immunization with Kexin/CD40L resulted in antibodies capable to protect in primary challenge experiments as well as in adoptive transfer experiments, and mediate opsonic phagocytosis of PC, which may be critical for its therapeutic effect. Furthermore, mice immunized with pKexin/CD40L showed significantly lower fungal burdens, with nearly 3-log greater protection compared to control CD4-depleted mice (Keely et al., 2003). These data provide clear proof of concept that DNA vaccination exploiting the expression of a key costimulatory molecule can support a host immune response also in the context of a CD4 deficiency.

\section{CONCLUSION}

Several reasons underlie the paucity of vaccination approaches to counteract fungal infection in immunocompromised hosts and identifying a niche patient population who could benefit from a cost-effective vaccine strategy is problematic, thus discouraging any efforts in this direction. Because responses to fungi depend on both arms of the immune response, there are formidable obstacles to identifying what are the key elements in translating preclinical models to a successful human vaccine. The timing of vaccination must be tailored to the time frame of risk to developing the disease and to the immunological features of patients. Pre- and post-transplant vaccination are both possible in SOT patients, while post-transplantation is the only option in HSCT. In addition, the high costs of preparing recombinant antigens for use in human studies that meet standards for Good Manufacturing Processes, poses a relevant issue of cost and timing to registration. Genetic vaccination offers a high degree of flexibility that potentially addresses these issues.

Genetic vaccination allows for the rapid and simultaneous screening of suitable antigens, selecting a candidate target that potentially provides cross reaction with other fungal antigens, thus laying the basis for pan vaccine development. Recommendation for immunization of SOT patients, already in place for other infectious diseases (Blanchard-Rohner et al., 2019), would certainly benefit pre- post- transplant vaccination able to cover a wider range of fungal infections. Genomic vaccination offers the flexibility to potentially overcome the complexity of the host immune status, particularly evident in HSCT and SOT patients. Both SOT and HSCT share the polarization of $\mathrm{CD}^{+}$cells toward the Th2 phenotype that significantly correlates with the risk of contracting fungal infection (Elenkov, 2004). The most important CD4 ${ }^{+} \mathrm{T}$ cells in the antifungal immune response are the Th1 and Th17 helper $\mathrm{T}$ cells. Th1 helper $\mathrm{T}$ cells secrete the cytokines IFN- $\gamma$ and TNF- $\alpha$ which not only are able to activate $T$ and $\mathrm{B}$ lymphocytes, but also innate immune cells, such as neutrophils, macrophages, DCs, and inflammatory monocytes, to fight against invading fungi. Genetic vaccination has the potential to redirect $\mathrm{CD}^{+}$lymphocyte immune response to Candida and Aspergillus toward a Th1 phenotype, for instance by co-expressing with the selected antigen a Th1 polarizing cytokine such as $\gamma$-IFN whose beneficial effect in fungal infections has already been demonstrated (Nagai et al., 1995; Sainz et al., 2007; Buddingh et al., 2015). As seen with pKexin/CD40 vaccination against PC, genetic vaccination could be programmed to overcome the low $\mathrm{CD}^{+}$lymphocyte cell count by co-expressing with the fungal antigens' costimulatory molecule able to vicariate $\mathrm{CD} 4{ }^{+}$lymphocytes and trigger a CD8 $\mathrm{T}$ lymphocytes immune response. Recent experience with the pandemic virus SARS-CoV2 have shown that genetic vaccines speed up development times and abate costs (Shin et al., 2020). Both these features are of considerable importance in developing therapies that require continuous checks in the clinical setting to adapt to the complexity of the interactions between host and fungi.

\section{AUTHOR CONTRIBUTIONS}

GS and LL wrote the review manuscript. EM revised the manuscript. All authors read and approved the submitted version. 


\section{REFERENCES}

Abu Abed, O. S. (2021). Gene therapy avenues and COVID-19 vaccines. Genes Immun. 22, 120-124. doi: 10.1038/s41435-021-00136-6

Ardiani, A., Higgins, J. P., and Hodge, J. W. (2010). Vaccines based on whole recombinant Saccharomyces cerevisiae cells. FEMS Yeast Res. 10, 1060-1069. doi: $10.1111 / j .1567-1364.2010 .00665 . \mathrm{x}$

Bacher, P., Jochheim-Richter, A., Mockel-Tenbrink, N., Kniemeyer, O., Wingenfeld, E., Alex, R., et al. (2015). Clinical-scale isolation of the total Aspergillus fumigatus-reactive T-helper cell repertoire for adoptive transfer. Cytotherapy 17, 1396-1405. doi: 10.1016/j.jcyt.2015.05.011

Banchereau, J., and Steinman, R. M. (1998). Dendritic cells and the control of immunity. Nature 392, 245-252. doi: 10.1038/32588

Barry, M. A., Howell, D. P. G., Andersson, H. A., Chen, J. L., and Singh, R. A. K. (2004). Expression library immunization to discover and improve vaccine antigens. Immunol. Rev. 199, 68-83. doi: 10.1111/j.0105-2896.2004.00143.x

Barry, M. A., Lai, W. C., and Johnston, S. A. (1995). Protection against mycoplasma infection using expression-library immunization. Nature 377, 632-635. doi: $10.1038 / 377632 \mathrm{a} 0$

Blanchard-Rohner, G., Enriquez, N., Lemaître, B., Cadau, G., Combescure, C., Giostra, E., et al. (2019). Usefulness of a systematic approach at listing for vaccine prevention in solid organ transplant candidates. Am. J. Transp. 19, 512-521. doi: 10.1111/ajt.15097

Bolhassani, A., and Yazdi, S. R. (2009). DNA immunization as an efficient strategy for vaccination. Avicenna J. Med. Biotechnol. 1, 71-88.

Bongomin, F., Gago, S., Oladele, R. O., and Denning, D. W. (2017). Global and multi-national prevalence of fungal diseases-estimate precision. J. Fungi. 3:57. doi: 10.3390/jof3040057

Bozza, S., Clavaud, C., Giovannini, G., Fontaine, T., Beauvais, A., Sarfati, J., et al. (2009). Immune sensing of Aspergillus fumigatus proteins, glycolipids, and polysaccharides and the impact on Th immunity and vaccination. J. Immunol. 183, 2407-2414. doi: 10.4049/jimmunol.0900961

Bozza, S., Gaziano, R., Lipford, G. B., Montagnoli, C., Bacci, A., Di Francesco, P., et al. (2002). Vaccination of mice against invasive aspergillosis with recombinant Aspergillus proteins and $\mathrm{CpG}$ oligodeoxynucleotides as adjuvants. Microbes. Infect. 4, 1281-1290. doi: 10.1016/s1286-4579(02)00007-2

Brandhorst, T. T., Wüthrich, M., Warner, T., and Klein, B. (1999). Targeted gene disruption reveals an adhesin indispensable for pathogenicity of Blastomyces dermatitidis. J. Exp. Med. 189, 1207-1216. doi: 10.1084/jem.189.8.1207

Buddingh, E. P., Leentjens, J., van der Lugt, J., Dik, W. A., Gresnigt, M. S., Netea, M. G., et al. (2015). Interferon-gamma immunotherapy in a patient with refractory disseminated candidiasis. Pediatr. Infect. Dis. J. 34, 1391-1394. doi: 10.1097/INF.0000000000000909

Capilla, J., Clemons, K. V., Liu, M., Levine, H. B., and Stevens, D. A. (2009). Saccharomyces cerevisiae as a vaccine against coccidioidomycosis. Vaccine 27, 3662-3668. doi: 10.1016/j.vaccine.2009.03.030

Cassone, A. (2013). Development of vaccines for Candida albicans: fighting a skilled transformer. Nat. Rev. Microbiol. 11, 884-891. doi: 10.1038/ nrmicro3156

Champer, J., Ito, J. I., Clemons, K. V., Stevens, D. A., and Kalkum, M. (2016) Proteomic analysis of pathogenic fungi reveals highly expressed conserved cell wall proteins. J. Fungi. 2:6. doi: 10.3390/jof2010006

Clark, E. A., and Ledbetter, J. A. (1994). How B and T cells talk to each other. Nature 367, 425-428. doi: 10.1038/367425a0

Cox, R. A., and Magee, D. M. (1998). Protective immunity in coccidioidomycosis. Res. Immunol. 149, 417-428. doi: 10.1016/s0923-2494(98)80765-7

de Almeida, J. N., Peçanha-Pietrobom, P. M., and Colombo, A. L. (2018). Paracoccidioidomycosis in Immunocompromised Patients: a literature review. J. Fungi. 5:E2. doi: 10.3390/jof5010002

de Amorim, J., Magalhães, A., Muñ;oz, J. E., Rittner, G. M. G., Nosanchuk, J. D., Travassos, L. R., et al. (2013). DNA vaccine encoding peptide P10 against experimental paracoccidioidomycosis induces long-term protection in presence of regulatory T cells. Microbes. Infect. 15, 181-191. doi: 10.1016/j. micinf.2012.11.007

De Bernardis, F., Amacker, M., Arancia, S., Sandini, S., Gremion, C., Zurbriggen, R., et al. (2012). A virosomal vaccine against candidal vaginitis: immunogenicity, efficacy and safety profile in animal models. Vaccine 30, 4490-4498. doi: 10.1016/j.vaccine.2012.04.069
Decken, K., Köhler, G., Palmer-Lehmann, K., Wunderlin, A., Mattner, F., Magram, J., et al. (1998). Interleukin-12 is essential for a protective Th1 response in mice infected with Cryptococcus neoformans. Infect. Immun. 66, 4994-5000. doi: 10.1128/IAI.66.10.4994-5000.1998

Devi, S. J. (1996). Preclinical efficacy of a glucuronoxylomannan-tetanus toxoid conjugate vaccine of Cryptococcus neoformans in a murine model. Vaccine 14, 841-844. doi: 10.1016/0264-410x(95)00256-z

di Francesco, P., Gaziano, R., Casalinuovo, I. A., Belogi, L., Palamara, A. T., Favalli, C., et al. (1994). Combined effect of fluconazole and thymosin alpha 1 on systemic candidiasis in mice immunosuppressed by morphine treatments. Clin. Exp. Immunol. 97, 347-352. doi: 10.1111/j.1365-2249.1994.tb06093.x

Diaz-Arevalo, D., Bagramyan, K., Hong, T. B., Ito, J. I., and Kalkum, M. (2011). CD4+ T cells mediate the protective effect of the recombinant Asp f3-based anti-aspergillosis vaccine. Infect. Immun. 79, 2257-2266. doi: 10.1128/IAI. 01311- 10

Diaz-Arevalo, D., Ito, J. I., and Kalkum, M. (2012). Protective effector cells of the recombinant asp f3 anti-aspergillosis vaccine. Front. Microbiol. 3:299. doi: 10.3389/fmicb.2012.00299

Edwards, J. E. (2012). Fungal cell wall vaccines: an update. J. Med. Microbiol. 61, 895-903. doi: 10.1099/jmm.0.041665-0

Elenkov, I. J. (2004). Glucocorticoids and the Th1/Th2 balance. Ann. NY Acad. Sci. 1024, 138-146. doi: 10.1196/annals.1321.010

Espinosa, V., and Rivera, A. (2016). First line of defense: innate cell-mediated control of pulmonary aspergillosis. Front. Microbiol. 7:272. doi: 10.3389/fmicb. 2016.00272

Flingai, S., Czerwonko, M., Goodman, J., Kudchodkar, S. B., Muthumani, K., and Weiner, D. B. (2013). Synthetic DNA vaccines: improved vaccine potency by electroporation and co-delivered genetic adjuvants. Front. Immunol. 4:354. doi: 10.3389/fimmu.2013.00354

Galgiani, J. N., Ampel, N. M., Blair, J. E., Catanzaro, A., Johnson, R. H., Stevens, D. A., et al. (2005). Coccidioidomycosis. Clin. Infect. Dis. 41, 1217-1223. doi: $10.1086 / 496991$

Gavaldà, J., Meije, Y., Fortún, J., Roilides, E., Saliba, F., Lortholary, O., et al. (2014). Invasive fungal infections in solid organ transplant recipients. Clin. Microbiol. Infect. 20, 27-48. doi: 10.1111/1469-0691.12660

Gingerich, A. D., Norris, K. A., and Mousa, J. J. (2021). Pneumocystis pneumonia: immunity, vaccines, and treatments. Pathogens 10:236. doi: 10 . 3390/pathogens 10020236

Grewal, I. S., and Flavell, R. A. (1998). CD40 and CD154 in cell-mediated immunity. Annu. Rev. Immunol. 16, 111-135. doi: 10.1146/annurev.immunol. 16.1.111

Gudding, R., and Naess, B. (1986). Vaccination of cattle against ringworm caused by Trichophyton verrucosum. Am. J. Vet. Res. 47, 2415-2417.

Hamad, M. (2012). Universal fungal vaccines: could there be light at the end of the tunnel? Hum. Vaccin. Immunother. 8, 1758-1763. doi: 10.4161/hv.2 1838

Hogan, L. H., Klein, B. S., and Levitz, S. M. (1996). Virulence factors of medically important fungi. Clin. Microbiol. Rev. 9, 469-488. doi: 10.1128/CMR.9.4.469

Ito, J. I., and Lyons, J. M. (2002). Vaccination of corticosteroid immunosuppressed mice against invasive pulmonary aspergillosis. J. Infect. Dis. 186, 869-871. doi: $10.1086 / 342509$

Ito, J. I., Lyons, J. M., Diaz-Arevalo, D., Hong, T. B., and Kalkum, M. (2009). Vaccine progress. Med. Mycol. 47, S394-S400. doi: 10.1080/ 13693780802552614

Ito, J. I., Lyons, J. M., Hong, T. B., Tamae, D., Liu, Y.-K., Wilczynski, S. P., et al. (2006). Vaccinations with recombinant variants of Aspergillus fumigatus allergen Asp f 3 protect mice against invasive aspergillosis. Infect. Immun. 74, 5075-5084. doi: 10.1128/IAI.00815-06

Ivey, F. D., Magee, D. M., Woitaske, M. D., Johnston, S. A., and Cox, R. A. (2003) Identification of a protective antigen of Coccidioides immitis by expression library immunization. Vaccine 21, 4359-4367. doi: 10.1016/S0264-410X(03) 00485-7

Iyalla, C. (2017). A review of the virulence factors of pathogenic fungi. African J. Clin. Exp. Microbiol. 18, 53-58. doi: 10.4314/ajcem.v18i1.8

Jiang, C., Magee, D. M., and Cox, R. A. (1999a). Coadministration of interleukin 12 expression vector with antigen 2 cDNA enhances induction of protective immunity against Coccidioides immitis. Infect. Immun. 67, 5848-5853. doi: 10.1128/IAI.67.11.5848-5853.1999 
Jiang, C., Magee, D. M., Quitugua, T. N., and Cox, R. A. (1999b). Genetic vaccination against Coccidioides immitis: comparison of vaccine efficacy of recombinant antigen 2 and antigen 2 cDNA. Infect. Immun. 67, 630-635. doi: 10.1128/IAI.67.2.630-635.1999

Keely, S. P., Cushion, M. T., and Stringer, J. R. (2003). Diversity at the locus associated with transcription of a variable surface antigen of Pneumocystis carinii as an index of population structure and dynamics in infected rats. Infect. Immun. 71, 47-60. doi: 10.1128/IAI.71.1.47-60.2003

Kolls, J. K., Habetz, S., Shean, M. K., Vazquez, C., Brown, J. A., Lei, D., et al. (1999). IFN-gamma and CD8+ T cells restore host defenses against Pneumocystis carinii in mice depleted of CD4+ T cells. J. Immunol. 162, 2890-2894.

Kontoyiannis, D. P., Marr, K. A., Park, B. J., Alexander, B. D., Anaissie, E. J., Walsh, T. J., et al. (2010). Prospective surveillance for invasive fungal infections in hematopoietic stem cell transplant recipients, 2001-2006: overview of the transplant-associated infection surveillance network (TRANSNET) database. Clin. Infect. Dis. 50, 1091-1100. doi: 10.1086/651263

Kumaresan, P. R., Manuri, P. R., Albert, N. D., Maiti, S., Singh, H., Mi, T., et al. (2014). Bioengineering $\mathrm{T}$ cells to target carbohydrate to treat opportunistic fungal infection. Proc. Natl. Acad. Sci. USA 111, 10660-10665. doi: 10.1073/ pnas. 1312789111

Kutzler, M. A., and Weiner, D. B. (2008). DNA vaccines: ready for prime time? Nat. Rev. Genet. 9, 776-788. doi: 10.1038/nrg2432

Larsen, R. A., Pappas, P. G., Perfect, J., Aberg, J. A., Casadevall, A., Cloud, G. A., et al. (2005). Phase I evaluation of the safety and pharmacokinetics of murinederived anticryptococcal antibody $18 \mathrm{~B} 7$ in subjects with treated cryptococcal meningitis. Antimicrob. Agents Chemother. 49, 952-958. doi: 10.1128/AAC.49. 3.952-958.2005

Lass-Flörl, C. (2009). The changing face of epidemiology of invasive fungal disease in Europe. Mycoses 52, 197-205. doi: 10.1111/j.1439-0507.2009.01691.x

Liu, M., Clemons, K. V., Bigos, M., Medovarska, I., Brummer, E., and Stevens, D. A. (2011). Immune responses induced by heat killed Saccharomyces cerevisiae: a vaccine against fungal infection. Vaccine 29, 1745-1753. doi: 10.1016/j.vaccine. 2010.12.119

Marques, A. F., daSilva, M. B., Juliano, M. A. P., Travassos, L. R., and Taborda, C. P. (2006). Peptide immunization as an adjuvant to chemotherapy in mice challenged intratracheally with virulent yeast cells of Paracoccidioides brasiliensis. Antimicrob. Agents Chemother. 50, 2814-2819. doi: 10.1128/AAC. 00220-06

Marr, K. A., Carter, R. A., Boeckh, M., Martin, P., and Corey, L. (2002) Invasive aspergillosis in allogeneic stem cell transplant recipients: changes in epidemiology and risk factors. Blood 100, 4358-4366. doi: 10.1182/blood-200205- 1496

McAllister, F., Mc Allister, F., Steele, C., Zheng, M., Young, E., Shellito, J. E., et al. (2004). T cytotoxic-1 CD8+ T cells are effector cells against pneumocystis in mice. J. Immunol. 172, 1132-1138. doi: 10.4049/jimmunol.172.2.1132

McCotter, O. Z., Benedict, K., Engelthaler, D. M., Komatsu, K., Lucas, K. D., MohleBoetani, J. C., et al. (2019). Update on the Epidemiology of coccidioidomycosis in the United States. Med. Mycol. 57, S30-S40. doi: 10.1093/mmy/myy095

Mehrad, B., Strieter, R. M., and Standiford, T. J. (1999). Role of TNF-alpha in pulmonary host defense in murine invasive aspergillosis. J. Immunol. 162 , 1633-1640.

Mezidi, M., Belafia, F., Nougaret, S., Pageaux, G. P., Conseil, M., Panaro, F., et al. (2014). Interferon gamma in association with immunosuppressive drugs withdrawal and antifungal combination as a rescue therapy for cerebral invasive Aspergillosis in a liver transplant recipient. Minerva. Anestesiol. 80, 1359-1360.

Morris, A., Lundgren, J. D., Masur, H., Walzer, P. D., Hanson, D. L., Frederick, T., et al. (2004). Current epidemiology of Pneumocystis pneumonia. Emerg. Infect. Dis. 10, 1713-1720. doi: 10.3201/eid1010.030985

Musso, T., Calosso, L., Zucca, M., Millesimo, M., Puliti, M., Bulfone-Paus, S., et al. (1998). Interleukin-15 activates proinflammatory and antimicrobial functions in polymorphonuclear cells. Infect. Immun. 66, 2640-2647. doi: 10.1128/IAI.66. 6.2640-2647.1998

Nagai, H., Guo, J., Choi, H., and Kurup, V. (1995). Interferon-gamma and tumor necrosis factor-alpha protect mice from invasive aspergillosis. J. Infect. Dis. 172, 1554-1560. doi: 10.1093/infdis/172.6.1554

Nami, S., Mohammadi, R., Vakili, M., Khezripour, K., Mirzaei, H., and Morovati, H. (2019). Fungal vaccines, mechanism of actions and immunology: A comprehensive review. Biomed. Pharmacother. 109, 333-344. doi: 10.1016/j. biopha.2018.10.075

Pathakumari, B., Liang, G., and Liu, W. (2020). Immune defence to invasive fungal infections: A comprehensive review. Biomed. Pharmacother. 130:110550. doi: 10.1016/j.biopha.2020.110550

Perruccio, K., Tosti, A., Burchielli, E., Topini, F., Ruggeri, L., Carotti, A., et al. (2005). Transferring functional immune responses to pathogens after haploidentical hematopoietic transplantation. Blood 106, 4397-4406. doi: 10. 1182/blood-2005-05-1775

Person, A. K., Kontoyiannis, D. P., and Alexander, B. D. (2010). Fungal infections in transplant and oncology patients. Infect. Dis. Clin. North Am. 24, 439-459. doi: 10.1016/j.idc.2010.01.002

Phan, Q. T., Myers, C. L., Fu, Y., Sheppard, D. C., Yeaman, M. R., Welch, W. H., et al. (2007). Als3 is a Candida albicans invasin that binds to cadherins and induces endocytosis by host cells. PLoS Biol. 5:e64. doi: 10.1371/journal.pbio. 0050064

Priest, S. J., Yadav, V., and Heitman, J. (2020). Advances in understanding the evolution of fungal genome architecture. F1000Res 9:254241. doi: 10.12688/ f1000research.25424.1

Rachini, A., Pietrella, D., Lupo, P., Torosantucci, A., Chiani, P., Bromuro, C. et al. (2007). An anti-beta-glucan monoclonal antibody inhibits growth and capsule formation of Cryptococcus neoformans in vitro and exerts therapeutic, anticryptococcal activity in vivo. Infect. Immun. 75, 5085-5094. doi: 10.1128/ IAI.00278-07

Ramirez-Ortiz, Z. G., Lee, C. K., Wang, J. P., Boon, L., Specht, C. A., and Levitz, S. M. (2011). A nonredundant role for plasmacytoid dendritic cells in host defense against the human fungal pathogen Aspergillus fumigatus. Cell Host Microbe. 9, 415-424. doi: 10.1016/j.chom.2011.04.007

Robbins, N., Wright, G. D., and Cowen, L. E. (2016). Antifungal drugs: the current armamentarium and development of new agents. Microbiol. Spectr. 4:16. doi: 10.1128/microbiolspec.FUNK-0002-2016

Romani, L., Puccetti, P., and Bistoni, F. (1997). Interleukin-12 in infectious diseases. Clin. Microbiol. Rev. 10, 611-636. doi: 10.1128/CMR.10.4.611

Safdar, A., Rodriguez, G., Zuniga, J., Akhrass, F. A., Georgescu, G., and Pande, A. (2013). Granulocyte macrophage colony-stimulating factor in 66 patients with myeloid or lymphoid neoplasms and recipients of hematopoietic stem cell transplantation with invasive fungal disease. Acta Haematol. 129, 26-34. doi: $10.1159 / 000342121$

Sainz, J., Pérez, E., Hassan, L., Moratalla, A., Romero, A., Collado, M. D., et al. (2007). Variable number of tandem repeats of TNF receptor type 2 promoter as genetic biomarker of susceptibility to develop invasive pulmonary aspergillosis. Hum. Immunol. 68, 41-50. doi: 10.1016/j.humimm.2006.10.011

Sam, Q. H., Yew, W. S., Seneviratne, C. J., Chang, M. W., and Chai, L. Y. A. (2018). Immunomodulation as therapy for fungal infection: are we closer? Front. Microbiol. 9:1612. doi: 10.3389/fmicb.2018.01612

Santos, E., and Levitz, S. M. (2014). Fungal vaccines and immunotherapeutics. Cold Spring Harb. Perspect. Med. 4:a019711. doi: 10.1101/cshperspect.a019711

Schmidt, C. S., White, C. J., Ibrahim, A. S., Filler, S. G., Fu, Y., Yeaman, M. R., et al. (2012). NDV-3, a recombinant alum-adjuvanted vaccine for Candida and Staphylococcus aureus, is safe and immunogenic in healthy adults. Vaccine 30, 7594-7600. doi: 10.1016/j.vaccine.2012.10.038

Schmiedel, Y., and Zimmerli, S. (2016). Common invasive fungal diseases: an overview of invasive candidiasis, aspergillosis, cryptococcosis, and Pneumocystis pneumonia. Swiss. Med. Wkly 146:w14281. doi: 10.4414/smw. 2016.14281

Scriven, J. E., Tenforde, M. W., Levitz, S. M., and Jarvis, J. N. (2017). Modulating host immune responses to fight invasive fungal infections. Curr. Opin. Microbiol. 40, 95-103. doi: 10.1016/j.mib.2017.10.018

Seidel, M. G., Peters, C., Wacker, A., Northoff, H., Moog, R., Boehme, A., et al. (2008). Randomized phase III study of granulocyte transfusions in neutropenic patients. Bone Marrow Transp. 42, 679-684. doi: 10.1038/bmt.2008.237

Sharma, A. K., and Khuller, G. K. (2001). DNA vaccines: future strategies and relevance to intracellular pathogens. Immunol. Cell Biol. 79, 537-546. doi: 10. 1046/j.1440-1711.2001.01044.x

Shibasaki, S., Aoki, W., Nomura, T., Karasaki, M., Sewaki, T., and Ueda, M. (2014). Evaluation of Mdh1 protein as an antigenic candidate for a vaccine against candidiasis. Biocontrol Sci. 19, 51-55. doi: 10.4265/bio.19.51 
Shin, M. D., Shukla, S., Chung, Y. H., Beiss, V., Chan, S. K., Ortega-Rivera, O. A., et al. (2020). COVID-19 vaccine development and a potential nanomaterial path forward. Nat. Nanotechnol. 15, 646-655. doi: 10.1038/s41565-020-0737-y

Silva, S. S., Paes, H. C., Soares, C. M. A., Fernandes, L., and Felipe, M. S. S. (2008). Insights into the pathobiology of Paracoccidioides brasiliensis from transcriptome analysis: advances and perspectives. Mycopathologia 165, 249258. doi: 10.1007/s11046-007-9071-2

Spellberg, B., Ibrahim, A. S., Yeaman, M. R., Lin, L., Fu, Y., Avanesian, V., et al. (2008). The antifungal vaccine derived from the recombinant $\mathrm{N}$ Terminus of Als3p protects mice against the bacterium staphylococcus aureus. Infect. Immun. 76, 4574-4580. doi: 10.1128/IAI.00700-08

Stephen-Victor, E., Karnam, A., Fontaine, T., Beauvais, A., Das, M., Hegde, P., et al. (2017). Aspergillus fumigatus cell wall $\alpha$-(1,3)-Glucan stimulates regulatory T-Cell Polarization by inducing PD-L1 expression on human dendritic cells. J. Infect. Dis. 216, 1281-1294. doi: 10.1093/infdis/jix469

Stuehler, C., Khanna, N., Bozza, S., Zelante, T., Moretti, S., Kruhm, M., et al. (2011). Cross-protective TH1 immunity against Aspergillus fumigatus and Candida albicans. Blood 117, 5881-5891. doi: 10.1182/blood-2010-12-325084

Stuehler, C., Kuenzli, E., Jaeger, V. K., Baettig, V., Ferracin, F., Rajacic, Z., et al. (2015). Immune reconstitution after allogeneic hematopoietic stem cell transplantation and association with occurrence and outcome of invasive aspergillosis. J. Infect. Dis. 212, 959-967. doi: 10.1093/infdis/jiv143

Taborda, C. P., Juliano, M. A., Puccia, R., Franco, M., and Travassos, L. R. (1998). Mapping of the T-cell epitope in the major 43-kilodalton glycoprotein of Paracoccidioides brasiliensis which induces a Th-1 response protective against fungal infection in BALB/c mice. Infect. Immun. 66, 786-793. doi: 10.1128/IAI. 66.2.786-793.1998

Taborda, C. P., Uran, M. E., Nosanchuk, J. D., and Travassos, L. R. (2015). Paracoccidioidomycosis: Challenges in the development of vaccine against an endemic mycosis in the Americas. Rev. Inst. Med. Trop. Sao Paulo 57, 21-24. doi: 10.1590/S0036-46652015000700005

Torosantucci, A., Bromuro, C., Chiani, P., De Bernardis, F., Berti, F., Galli, C., et al. (2005). A novel glyco-conjugate vaccine against fungal pathogens. J. Exp. Med. 202, 597-606. doi: 10.1084/jem.20050749

Torosantucci, A., Chiani, P., Bromuro, C., De Bernardis, F., Palma, A. S., Liu, Y., et al. (2009). Protection by anti-beta-glucan antibodies is associated with restricted beta-1,3 glucan binding specificity and inhibition of fungal growth and adherence. PLoS One 4:e5392. doi: 10.1371/journal.pone.000 5392

Tverdek, F. P., Kofteridis, D., and Kontoyiannis, D. P. (2016). Antifungal agents and liver toxicity: a complex interaction. Expert. Rev. Anti Infect. Ther. 14, 765-776. doi: 10.1080/14787210.2016.1199272

Vilanova, M., Teixeira, L., Caramalho, I., Torrado, E., Marques, A., Madureira, P., et al. (2004). Protection against systemic candidiasis in mice immunized with secreted aspartic proteinase 2. Immunology 111, 334-342. doi: 10.1111/j.13652567.2004.01819.x

Voigt, J., Hünniger, K., Bouzani, M., Jacobsen, I. D., Barz, D., Hube, B., et al. (2014). Human natural killer cells acting as phagocytes against Candida albicans and mounting an inflammatory response that modulates neutrophil antifungal activity. J. Infect. Dis. 209, 616-626. doi: 10.1093/infdis/jit574
Wan, L., Zhang, Y., Lai, Y., Jiang, M., Song, Y., Zhou, J., et al. (2015). Effect of granulocyte-macrophage colony-stimulating factor on prevention and treatment of invasive fungal disease in recipients of allogeneic stem-cell transplantation: a prospective multicenter randomized phase IV trial. JCO 33, 3999-4006. doi: 10.1200/JCO.2014.60.5121

Wiederhold, N. P. (2017). Antifungal resistance: current trends and future strategies to combat. Infect. Drug Resist. 10, 249-259. doi: 10.2147/IDR.S124918

Winn, R. M., Gil-Lamaignere, C., Roilides, E., Simitsopoulou, M., Lyman, C. A., Maloukou, A., et al. (2003). Selective effects of interleukin (IL)-15 on antifungal activity and IL-8 release by polymorphonuclear leukocytes in response to hyphae of Aspergillus species. J. Infect. Dis. 188, 585-590. doi: 10.1086/377099

Wozniak, K. L., Young, M. L., and Wormley, F. L. (2011). Protective immunity against experimental pulmonary cryptococcosis in T cell-depleted mice. Clin. Vaccine Immunol. 18, 717-723. doi: 10.1128/CVI.00036-11

Wüthrich, M., Filutowicz, H. I., and Klein, B. S. (2000). Mutation of the WI1 gene yields an attenuated blastomyces dermatitidis strain that induces host resistance. J. Clin. Invest. 106, 1381-1389. doi: 10.1172/JCI11037

Xin, H., Cartmell, J., Bailey, J. J., Dziadek, S., Bundle, D. R., and Cutler, J. E. (2012). Self-adjuvanting glycopeptide conjugate vaccine against disseminated candidiasis. PLoS One 7:e35106. doi: 10.1371/journal.pone.0035106

Xue, J., Chen, X., Selby, D., Hung, C.-Y., Yu, J.-J., and Cole, G. T. (2009). A genetically engineered live attenuated vaccine of Coccidioides posadasii protects $\mathrm{BALB} / \mathrm{c}$ mice against coccidioidomycosis. Infect. Immun. 77, 31963208. doi: 10.1128/IAI.00459-09

Yoon, H. J., and Clemons, K. V. (2013). Vaccines against Coccidioides. Korean J. Intern. Med 28, 403-407. doi: 10.3904/kjim.2013.28.4.403

Zheng, M., Ramsay, A. J., Robichaux, M. B., Norris, K. A., Kliment, C., Crowe, C., et al. (2005). CD4+ T cell-independent DNA vaccination against opportunistic infections. J. Clin. Invest. 115, 3536-3544. doi: 10.1172/JCI26306

Conflict of Interest: LL, GS, GR, and EM were employed by Takis s.r.l., that is a commercial entity.

The remaining authors declare that the research was conducted in the absence of any commercial or financial relationships that could be construed as a potential conflict of interest.

Publisher's Note: All claims expressed in this article are solely those of the authors and do not necessarily represent those of their affiliated organizations, or those of the publisher, the editors and the reviewers. Any product that may be evaluated in this article, or claim that may be made by its manufacturer, is not guaranteed or endorsed by the publisher.

Copyright (c) 2021 Luberto, Neroni, Gandini, Fiscarelli, Salvatori, Roscilli and Marra. This is an open-access article distributed under the terms of the Creative Commons Attribution License (CC BY). The use, distribution or reproduction in other forums is permitted, provided the original author(s) and the copyright owner(s) are credited and that the original publication in this journal is cited, in accordance with accepted academic practice. No use, distribution or reproduction is permitted which does not comply with these terms. 